\title{
In the "Web" of Problems and Opportunities of Modern Multimedia Methods in Russia's Humanitarian Education
}

\author{
Irina Ponizovkina \\ Department of History and Philosophy \\ Plekhanov Russian University of Economics \\ Moscow, Russia \\ irina-ponizovkin@mail.ru
}

\author{
Elena Agibalova \\ Department of Foreign Languages \\ Plekhanov Russian University of Economics \\ Moscow, Russia \\ elenagib@rambler.ru
}

\begin{abstract}
The article presents relevant issues and opportunities of modern multimedia education at university. It focuses on the analysis of the impact that innovative methods and methodology implemented in the educational sphere have on the nature and quality of young experts' socialhumanitarian training. The authors rely in their conclusions on specific facts, identify and analyze contradictions arising in the course of educational reforms, present solutions to them.
\end{abstract}

Keywords-higher education; e-learning; multimedia learning tools; educational reform; social-humanitarian education

\section{INTRODUCTION}

Modern globalization processes, the development of the information society and the "knowledge" society had an impact on all social aspects including the educational sphere and resulted in widespread diffusion of new technology and methods of instruction. Transformation of educational practices status reflects the relevant trend of a shift to digital economy and the information society that is capable of developing into the knowledge society. Amid the development of information and communication technology, "the institute of instruction" extended far beyond the world of education itself and covered all the levels of economic and social life" that led to the establishment of new lifelong learning principles in the global society (A Memorandum of Lifelong Learning, the European Union, 2000) [1] [2].

Today, the Russian educational sphere also witnesses overall interest in multimedia tools and online methodology. Informatization is seen by the Russian Ministry of Education as one of the major methods for implementing innovations in the educational system and also its modernization to improve competitiveness [3]. It is connected both with new opportunities as a result of processes and technology development and with changes that took place due to the development of the information society where information and an ability to work with it are the main values. Already in 1998, the Russian Ministry of Education approved the Concept of Educational Sphere Informatization. In 2000, the project of the federal special-purpose program entitled "The
Development of Single Educational Information [http://elementy.ru/Library9/Progr630.htm-accessed date: 15.05.2017] was approved.

\section{OBJECTIVES AND OPPORTUNITIES OF MULTIMEDIA LEARNING}

Today, innovative methods of instruction are presented by "ideologists" of new trends as a solution to numerous problems in modern higher education: cost-cutting, improvement of efficiency and quality. The Electronic Educational Environment (EEE) developed to make a single, accessible, low-cost (decrease the number of instructors, classrooms, library stock, etc.) and controllable learning process is being urgently implemented. Tools of educational and scientific communications are changing as well as methodology of modern education and knowledge control. Indeed, different multimedia tools are able to solve many problems in the course of university studies: the biggest advantage in this case could be new opportunities of inclusive education for physically or mentally challenged young people who see new horizons opening for them taking into consideration the diversity of their unique educational requirements and individual needs. New methods are a huge support for students following online or one-on-one study courses. Under such conditions online learning departments and universities are created, some of them are able to surpass state and national borders and provide generally accessible education.

With the help of new virtual means, advocates of "Bologna" education see their dream of standardizing the studying process and knowledge quality control come true. To a certain extent, there is nothing wrong with this intention. To get rid of excessively biased instructors and disparate learning requirements at different universities and those put forward by different instructors is a good initiative and it also allows maintaining a certain educational benchmark. In this sense, one can say that it was a right decision to introduce the Uniform state exam at schools when it was necessary to have a single standard in the educational system as 
requirements in various educational institutions and those put forward by various instructors differed greatly.

The only problem is to which extent these innovations should be implemented, how peculiar features of disciplines need to be considered and when to stop so that a good initiative does not result in the reverse effect. For instance, the use of technical means and information systems to monitor students' knowledge has its own advantage: realtime objective information on students' assimilation of the material, an opportunity to present this information to the instructor personally and in detail, development and accumulation of integral (ranking) students' performance appraisal in all disciplines and modules of the educational program, development of practical competencies and skills of operations with information means and resources, an opportunity of students' self-control and motivation in the course of individual studies. These advantages mostly have a formal character and formal benefits which in a number of cases and disciplines are obviously not enough to master competences. The fact that we are limited to only these electronic means of intermediate and final control dilutes, for example, the essence of philosophic-humanitarian education, which is actually dialogical, and thus they can be applied in this sphere only as support.

It would be fair to admit that multimedia tools have considerably extended the forms and ways of organizing educational-scientific communications, which could be considered irreplaceable under certain conditions. These are virtual interaction means in the form of online conferences, webinars, video lectures, online consultations, scientific communities as "invisible colleges" etc.

IT experts that were invited to find a solution to this problem are already dreaming about the near future when all the learning processes will be virtual. Universities' newsfeeds happily inform us on the introduction of new "web" education. However, one should be careful so that this global web does not become a trap for modern education - at least, for social and humanitarian education.

\section{MODERN MUlTiMediA SOCIETY AND PROBLEMS OF INSTRUCTION}

Instruction of social and humanitarian disciplines is an entirely unique phenomenon - in terms of the mission, actual challenges and methods of instruction. However, in the age of global standardization, unification and pragmatism it is not common to stand out against all others at a university that has certain specification (economic, technical, etc.). So, social and humanitarian courses quickly find themselves among those that are not promising. That is why "the number of introductory, general courses is reducing and major emphasis is made instead on professional skills" [4].

In our postmodernity era, when relativism and pragmatism are dominating in terms of values, including educational values, it is not surprising that there is an academic-methodological trend of developing sector-specific, applied and instrumental courses to the disadvantage of basic profound education based on the comprehension of philosophic-humanitarian sense of current processes and mastering of ethical- axiological approaches. In general, it complies with clipping, mosaic consciousness. The creation of the information society and postmodern trends accelerate each other in the development of modern mosaic-"split" consciousness, which manifests its domination in the educational sphere to the fullest extent [5]. Principles of scientific rationality and deterministic vision of the surrounding reality are substituted with skepticism towards the ability to come to know social life and a human as functioning systems. Deconstruction, which is characteristic of postmodernity, destroys the perception of a targeted cognitive process that grasps the meaning and laws of what is happening around. Developed multimedia technology (TV, Internet, advertising, etc.) with a kaleidoscope of news, random facts, imposing of diverse senses, alternating storylines and emphasis on success result in abandoned search of a vector in the development of social processes and its substitution with technologization of approaches [6].

But should one fall for a thinking that has been developed by modern computer and video technology? As in this case a person loses a lot of rational thinking skills required to master university educational content. Even the identification of basic interconnections between contents of academic courses is difficult for a modern student. This way, learners' knowledge is not harmoniously structured so that it could be updated when necessary.

Then we see a student type of thinking emerging when he/she abandons attempts of clearly systemizing knowledge about the world, does not use basic notions and deletes the demarcation line between scientific and ordinary cognition. "Everyone has their own opinion!", the slogan that has become a principle, is enough to be a substitute for the process of studying reliable facts, scientific literature and theory of logical argumentation. To our mind, the reason for such a superficial cognitive process among modern students is insufficient mastering of fundamental principles and cognition basics. Methodological lack of foresight among educational organizers results in deterioration of its quality.

Special researches carried out by L. Vekker and G. Crabtree from Stanford University suggest a generally decreasing human intelligence level [7]. It appears that the Bologna process has had no small share in this process. L. Yasukova, Head of social psychology laboratory at St. Petersburg State University, Head of "Diagnostics and Development of Capabilities" Center, also identified a similar trend in Russia based on monitoring of schoolchildren and students' intellectual development. She thinks that less than $20 \%$ of modern young people have comprehensive conceptual thinking [8]. Only true and thorough knowledge that acquires systematic character in human mind has a real control (over circumstances, phenomena, nature, etc.). Amid modern conditions of a constantly changing world, unstable social systems and cataclysms, the risk of catastrophic consequences of wrong subjective decisions is too high. 


\section{DRAWBACKS OF ELECTRONIC DIGITAL EDUCATION}

Modern information technology transforms knowledge into an informational resource of the society. Now this technology, rather than books, store, process and transfer information. It seems that it should facilitate and accelerate the learning process and increase the share of students' individual work. However, the problem, which can be called the problem of false expertise that western countries faced in the second half of the XX century, originates here. Young people who master IT-technology turned out to be incapable of processing an information array they dealt with. It manifested itself through inability to identify contradictions and discrepancies in the material under examination, inability to identify essential information even if the skill of information extraction is developed, insufficient knowledge of information structure and quality of information sources.

These problems are reveled in all shapes and sizes today in the Russian educational space. We see the emergence of false knowledge problem when a learner tries to substitute real knowledge with awareness and the possession of information files provides a feeling of mastering knowledge. It may result in seeming, "virtual" education of listeners who, due to the insufficient development of their creative abilities, close-mindedness and limited basic knowledge, overall underdevelopment of rational-logical cognition methods are not able to work with the received information efficiently. It turns out that such "experts" are not able to identify "pressure points" of the phenomenon in question, to distinguish between the main and the secondary with the superficial, to creatively process and classify the information to solve certain issues, to link them with a certain situation, to have a broad look at surrounding reality. The development of such competencies is within the sphere of logicalphilosophical-humanitarian learning that, since Socrates, has relied on dialogical forms that are actually interactive.

No wonder that according to Catherine Weinberger, an economist from the University of California, Santa Barbara, in western countries, experts with a balanced (including general cultural component) set of competences receive $10 \%$ more than their "field-specific" colleagues [9].

Personality is forced out from the process of modern "virtual" education. This is the personality of a Teacherinstructor who is engaged in a heuristic dialogue with listeners and organizes the audience into a community of personalities who are ready for future endeavors. Today, as a result of excessive technologization of the learning process, the status of instructor-Personality and instructor-Scholar is brought down to the status of expert-inspector and a standard unit of scholar-spiritual production. Personal educational requests, needs and interests of young people can be fully satisfied only in the process of an inimitable dialogue with Teacher that cannot be substituted with any standard video lecture.

\section{CONCLUSION}

It may be admitted that the Bologna process with its unification and standardization of education is an attempt to control postmodernism chaos - an aspiration to rise above the moment and relativity by limiting them to certain competences and common standards. However, proactive attempts to use electronic resources to technologize Russian higher professional education that has become another service industry, have not received enough of spiritual support.

It should be kept in mind that higher education is, first of all, mastering of supreme intellectual and cultural values, enrichment of spiritual wealth and development of human capital. Humanitarian component in Russia has always played an important role in any academic profile [10]. It cannot be achieved amid excessive formalization that has become today the dominating vector in education. It is necessary to construct a multi-profile educational space that, on the one hand, would consider traditions and achievements in the development of national education in Russia and, on the other hand, would create optimal conditions to use and develop the potential of new information and communication technology in educational practices [11].

\section{REFERENCES}

[1] Towards Knowledge Societies / UNESCO world report (2005).// URL: http://unesdoc.unesco.org/images/0014/001418/141843r.pdf [accessed date: 15.05.2017]

[2] A Memorandum on Lifelong Learning / Commission of the European communities. URL:http:// ec.europa.eu/ education/Lifelong-learningpolicy/doc/policy/memo_en.pdf. [accessed date: 15.05.2017]

[3] On Federal Target Program of Education Development for 2006 2010 // URL: http://base.garant.ru/189041/ [accessed date: 15.05.2017]

[4] Shift to the Bologna Educational System in Russia May Turn Out to $\mathrm{Be} \quad \mathrm{a} \quad$ Failure // http://www.newsru.com/russia/19jul2006/bolonsky.html

[5] O. V. Chistyakova, Postmodernism, Christian Patristics, and values of peace in the modern cultures in the Context of Educational Process, the Proceedings of the 2016 International Conference on Arts, Design and Contemporary Education (ICADCE 2016), Published by Atlantis Press, 2016, pp. 994-999.

[6] I. Ponizovkina, E. Agibalova, The loss of life purpose as a problem of modern society, the Proceedings of the International Conference on Contemporary Education, Social Sciences and Humanities (ICCESSH 2016). Advances in Social Science, Education and Humanities Research. Paris: Atlantis Press, 2016, pp. 657-661.

[7] O. Chistyakova, Rationalization of contemporary culture and education in the context of religious resistance to violence, Proceedings of the 2016 International Conference on Arts, Design and Contemporary Education. (ICADCE 2016), Advances in Social Science, Education and Humanities Research, Moscow, Russia, Paris: Atlantis Press, 2016, Volume 64, pp. 1192-1198.

[8] The Gap Between Smart and Silly Increases. Interview of L. $\begin{array}{lll}\text { Yasukova to } & \text { Rosbalt. }\end{array}$ http://www.rosbalt.ru/main/2013/12/04/1207437.html [accessed date: 29.04.2017]

[9] G. Anders, There's no place for techies here: how humanitarians conquer Silicon Valley // http://www.forbes.ru/person/81689-andersdzhordzh [accessed date: 15.05.2017]

[10] I. Ponizovkina, Teaching of philosophy as a system core of modern higher education, Proceedings of the 2nd International Conference on Contemporary Education, Social Sciences and Humanities (ICCESSH 2017) Part of the series ASSEHR. Atlantis Press, 2017, pp.144-147.

[11] O. V. Chistyakova, Russian religious philosophy as the basis for state identity, Eurasian Research Journal. 2003, Vol. 2, No.1, pp. 13-17. 